\title{
CAKE KIDNEY DRAINED BY SINGLE URETER
}

\author{
ADRIANO A. CALADO, ANTONIO MACEDO JR., MIGUEL SROUGI \\ Section of Urology, Paulista School of Medicine, Federal University of São Paulo, UNIFESP, \\ São Paulo, Brazil
}

\begin{abstract}
Cake kidney is a rare congenital anomaly of the urogenital tract, with a few more than 20 cases described in the literature. It can be diagnosed at any age range. Normally, drainage is achieved by 2 ureters, and there are only 5 reports in the literature of cake kidney drained by a single ureter. The authors describe one more case of this rare malformation of the urinary tract.
\end{abstract}

Key words: kidney; abnormalities; ureter; hydronephrosis

Int Braz J Urol. 2004; 30: 321-2

\section{INTRODUCTION}

Cake kidney is a rare congenital anomaly of the urogenital tract, and it is normally drained by 2 ureters. There are only 5 reports in the literature of cake kidney drained by single ureter (1). The early diagnosis of potential complications that can accompany this anomaly must be always made in order to prevent permanent renal damage (2). The authors report one case of cake kidney manifested as hydronephrosis associated with urinary infection, and discuss the therapeutic approach.

\section{CASE REPORT}

Male, 5-months old child, presented a history of recurrent urinary tract infections. There was already a previous history of 2 hospitalizations due to acute pyelonephritis. At the moment, he was under antimicrobial prophylaxis with nitrofurantoin.

The patient underwent renal ultrasonography that revealed bilateral hydronephrosis, more pronounced on the right side. Voiding urethrocystography was normal. Renal scintigraphy (Figure-1) revealed the presence of a cystic renal mass with pelvic local- ization, with an obstructive pattern for clearance of radiopharmaceutical $\left(\mathrm{T}_{1 / 2}=39 \mathrm{~min}\right.$. $)$.

The child was operated due to suspicion of ureteropelvic junction (UPJ) stenosis in a single kid-

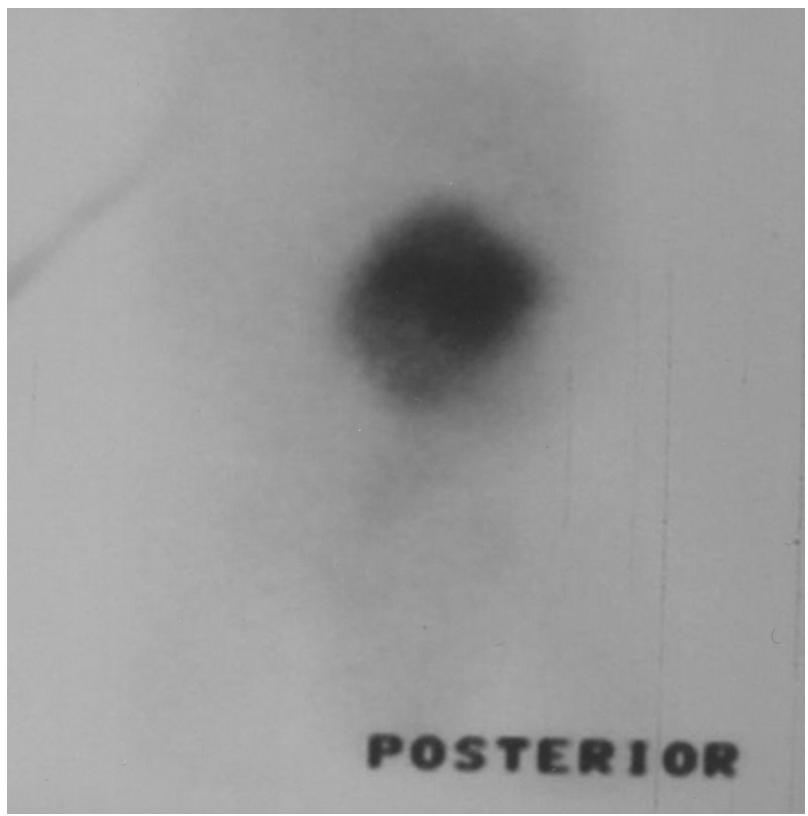

Figure 1 - Renal scintigraphy (DTPA) showing a single renal mass with radiopharmaceutical retention. 
ney. The surgical finding was cake kidney with pelvic location, presenting extra-renal calices. The ureter was single and presented moderate dilation (Figure-2). Due to the child's young age, a decompressive pyelotomy was performed. The child had a good outcome postoperatively, being discharged from the hospital on the fourth postoperative day. Currently he is under prophylaxis without new episodes of urinary infection.

\section{COMMENTS}

Cake kidney is a rare congenital malformation of the urogenital tract, which can be diagnosed at any age group, from childhood to the eightieth decade of life (3).

This anomaly occurs at an early phase in the embryological development (2). Under normal conditions, the 2 masses of metanephrogenic tissue arise in the pelvis and ascend to their definitive position in the lumbar region, bilaterally. During such migration, they undergo a lateral deviation, with axial deflection and internal rotation.

During the formation of a cake kidney, the nephrogenic blastemas would be compressed between the umbilical arteries at the beginning of the cranial migration of the ureteral buds, and this would leads to their fusion (2). Fused kidneys, such as the cake kidney, are prevented from ascending and remain in an ectopic pelvic position. The rare occurrence of a single ureter draining the fused renal mass can be caused by the regression of the second ureteral bud following the fusion of the metanephric blastemas (3).

The majority of diagnosed cases have been reported to present malformations in other organs or in their blood supply, such as abnormal testicular migration, Fallot's tetralogy, vaginal or sacral agenesia, anal abnormalities, among others (3).

The diagnosis of cake kidney is not necessarily associated with a poor prognosis. However, complications that can be associated with anatomic malformations such as urinary stasis, infection, formation of stones, and vascular involvement, can cause serious clinical problems (2). Therefore, cases of cake kidney must be investigated in order to exclude concomitant anomalies and to prevent complication.

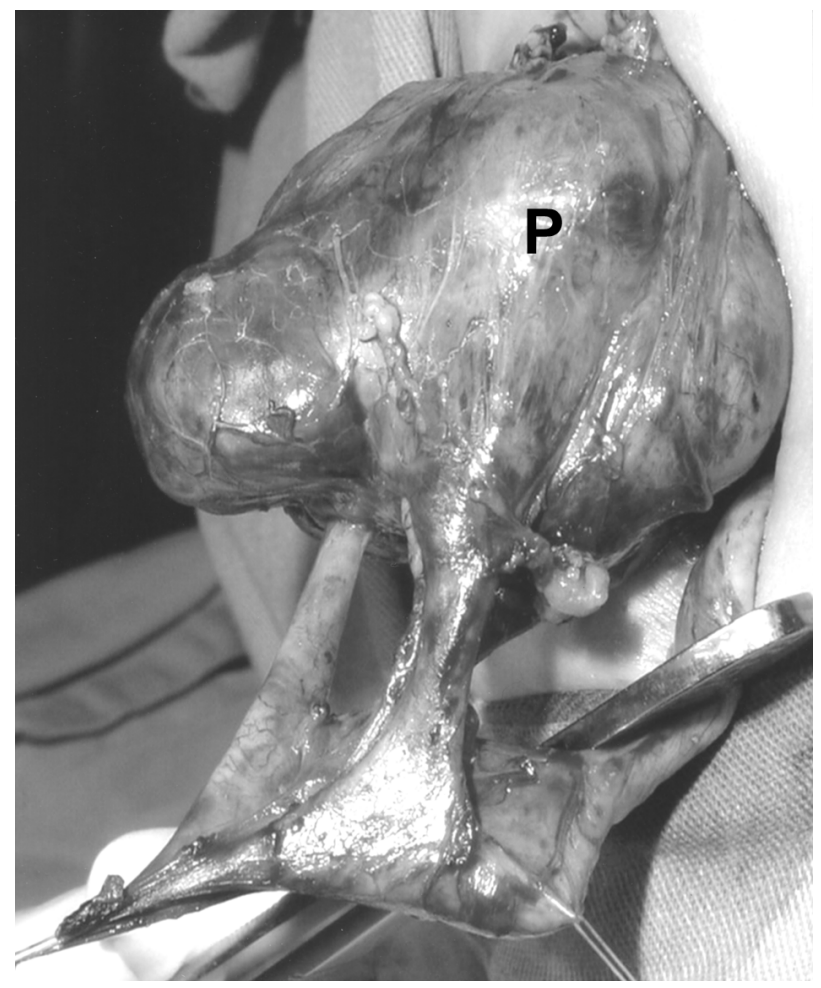

Figure 2 - Intra-operative finding of cake kidney. Note the dilated extra-renal pelvis $(P)$ and single ureter.

\section{REFERENCES}

1. Martinez-Lazaro R, Cortes-Blanco A.: A. Cake kidney drained by single ureter: MAG3 renogram for diagnosis and function follow-up. Nephrol Dial Transplant. 2000; 15: 1700-1.

2. Brock JW 3rd, Braren V, Phillips K, Winfield AC: Caudal regression with cake kidney and a single ureter: a case report. J Urol. 1983; 130: 535-6.

3. Goren E, Eidelman A: Pelvic cake kidney drained by single ureter. Urology. 1987; 30: 492-3.

Received: March 16, 2004

Accepted after revision: June 6, 2004

\footnotetext{
Correspondence address:

Dr. Adriano Almeida Calado

Rua Três de Maio, 17 / 31

04044-020, São Paulo, SP, Brazil

E-mail: aacalado@uol.com.br
} 